Sādhanā Vol. 37, Part 6, December 2012, pp. 731-737. (c) Indian Academy of Sciences

\title{
Stabilization of chromium salt in ordinary portland cement
}

\author{
DAMIR BARBIR*, PERO DABIĆ and PETAR KROLO \\ Department of Inorganic Technology, Faculty of Chemistry and Technology, \\ University of Split, Teslina 10, 21000 Split, Croatia \\ e-mail: dbarbir@ktf-split.hr; dabic@ktf-split.hr; krolo@ktf-split.hr
}

MS received 1 March 2012; revised 2 July 2012; accepted 27 August 2012

\begin{abstract}
Ordinary Portland cement (OPC) samples containing the chromium salt have been investigated using differential microcalorimetry, conductometry and Fourier transform infrared spectroscopic analysis. The effect of chromium on OPC hydration was evaluated by continuous observing of early hydration. The microcalorimetrical results show that with increasing the share of chromium salt, heat maximums assume lower values and the occurrence of the maximum registered in the earlier hydration times. Conductometrical measurements show that with increasing addition of chromium salt, curve did not show any specific shape, immediate drop in specific conductivity is noticed and the maximum is reached earlier. This coincides with microcalorimetrical results. It can be concluded that the addition of chromium does not affect the mechanism of the hydration process, but it does affect the kinetic parameters and dynamics of the cement hydration process. It was found that chromium salt addition to the cement-water system is acceptable up to $2 \mathrm{wt}$.\%. According to standard EN 196-3 for OPC, the beginning of binding time should occur after 60 minutes. Increased amount of chromium over $2 \mathrm{wt}$.\% significantly accelerate the beginning of binding time and for the system it is not acceptable.
\end{abstract}

Keywords. Stabilization/solidification; ordinary portland cement; ammonium dichromate; differential microcalorimetry; conductometry; Fourier transform infrared spectroscopy.

\section{Introduction}

The stabilization/solidification process of the chromium wastes generated from steel production, chrome plating, pigments and leather tanning industries is an important and complex issue (EPA 1994; Spence \& Shi 2005). Among the various forms of chromium, Cr(VI) is the most important one because of its toxicity, solubility and mobility (Katz \& Salem 1994; Bartlett 1991). $\mathrm{Cr}(\mathrm{VI})$ is a strong oxidizing agent and it is toxic to human, animals and plants and classified as a carcinogen (Wang \& Vipulanandan 2000; Shi \& Kan 2009).

*For correspondence 
Portland cement (OPC) is often used as the binding agent on its own, or in combination with cement replacement materials, which may be hydraulic (cement kiln dust) or pozzolanic (pulverized fuel ash, slag, etc.) in nature (Taylor 1997). The use of cementitious materials can significantly reduce the release of toxic species by providing an environment of high alkalinity. In many cases, there are complex interactions between waste components and binders (inhibiting or accelerating the normal hydration reaction) (Giergiczny \& Krol 2008).

Many studies have shown the effect of chromium on the Portland cement matrix. The study indicates that chromium is easily incorporated to the $\beta-\mathrm{C}_{2} \mathrm{~S}$ and common Portland cement pastes, but this affects the characteristics and the hydration products (Trezza \& Scian 2007). Otomoso et al (1995) investigated chromium stabilization in tricalcium silicate and they concluded that addition of $\mathrm{Cr}$ (III) accelerates the tricalcium silicate hydration until the $\mathrm{Cr}$ (IV) does not have any effect. Wang \& Vipulanandan (2000) concluded that addition of $\mathrm{Cr}(\mathrm{VI})$ in the form $\mathrm{K}_{2} \mathrm{CrO}_{4}$ extended the initial and final setting time and decreased the compressive strength. Zamorani et al (1989) discovered that low Cr(III) levels in cement system accelerated the setting time. Pera et al (1997) notified that the immobilization of $\mathrm{Cr}$ (VI) by hydraulic binders takes place by one or a combination of the following mechanisms: addition, substitution or precipitation of new components. Results show that Portland cement is the most efficient binder.

This paper has examined the effect of chromium salt on the hydration processes using different methods: differential microcalorimetry, conductometry and FTIR analysis. The main aim of this study is to determine an acceptable content of chromium salt in the cement system for its successful stabilization and solidification.

\section{Materials and methods}

\subsection{Materials and sample preparation}

All the measurements were carried on using ordinary Portland cement (OPC) and different content of ammonium dichromate. OPC (according to EN-197 CEM I) was obtained from CEMEX Croatia cement plant (Kaštel Sućurac, Croatia). Its chemical composition and physical properties are shown in tables 1 and 2. Ammonium dichromate, $\left(\mathrm{NH}_{4}\right)_{2} \mathrm{Cr}_{2} \mathrm{O}_{7}$, p.a., was obtained from Kemika plant, Zagreb, Croatia.

Samples for microcalorimetrical measurements were prepared by mixing cement and $0,1,2$, 3, 4 and $5 \mathrm{wt} . \%$ of ammonium dichromate. The total mass of the solid sample was constant and

Table 1. Chemical composition of OPC.

\begin{tabular}{lr}
\hline Composition & $(\%)$ \\
\hline $\mathrm{SiO}_{2}$ & 22.85 \\
$\mathrm{Al}_{2} \mathrm{O}_{3}$ & 4.81 \\
$\mathrm{Fe}_{2} \mathrm{O}_{3}$ & 2.79 \\
$\mathrm{CaO}$ & 65.23 \\
$\mathrm{MgO}$ & 1.61 \\
$\mathrm{~K}_{2} \mathrm{O}$ & 1.89 \\
$\mathrm{Na}_{2} \mathrm{O}$ & 0.18 \\
Loss of ignition & 0.04 \\
\hline
\end{tabular}


Table 2. Physical and mechanical properties of OPC.

\begin{tabular}{lc}
\hline Physical property & Value \\
\hline Specific surface according to Blaine $\left(\mathrm{cm}^{2} \mathrm{~g}^{-1}\right)$ & 3300 \\
Standard consistency $(\%)$ & 26 \\
Setting time - start (min) & 85 \\
Setting time - end (min) & 150 \\
Average flexural strength (MPa) & 6.26 \\
$\quad$ after 3 days & 8.44 \\
after 28 days & \\
Average compressive strength (MPa) & 33.5 \\
after 3 days & 50.7 \\
after 28 days & \\
\hline
\end{tabular}

it was $4 \mathrm{~g}$. A water to solid ratio of 0.5 was used for all mixes and measurements were carried out at a temperature of $20^{\circ} \mathrm{C}$.

Samples for conductometrical measurements were prepared in the same way as the samples for microcalorimetrical measurements, exept the total mass of the solid sample was $100 \mathrm{~g}$.

Cement pastes for FTIR analysis were hydrated 28 days in a thermostat at a temperature of $20^{\circ} \mathrm{C}$. After this curing time they were ground and sieved through a standard $4900 \mathrm{mesh} / \mathrm{cm}^{2}$ sieve.

\subsection{Methods}

2.2a Differential microcalorimetry: The microcalorimetrical measurements used to examine the interferences with a waste stabilization process were conducted by means of a differential microcalorimeter of the conduction-isoperibolic type (Krstulović et al 1989). An ALMEMO 2290-8 data logger was used to register heat effects of the hydration processes in the microcalorimeter, monitoring the change of voltage $\mathrm{d} U=f(t)$. The recorded values were processed by a computer program on a computer, obtaining the values of the hydration heat, the relative reaction degree, and the heat release rate for the given hydration conditions.

2.2b Conductivity: The conductometrical measurements were conducted by means of an ISKRA MA 5964 microprocessor conductometer connected to a computer via a RS $232 \mathrm{C}$ digital output. The conductometrical cell electrode was made of stainless steel with a constant $\mathrm{C}=$ $0.285 \mathrm{~cm}^{-1}$.

2.2c Fourier-transform infrared spectroscopy (FTIR): FTIR was performed with a Perkin Elmer Spectrum One spectrometer. Optically transparent discs were prepared in the mini-press from powdered samples mixed with $\mathrm{KBr}$. The scanning range was from 4000 to $450 \mathrm{~cm}^{-1}$ and the number of scans were 10 at a resolution of $4 \mathrm{~cm}^{-1}$.

\section{Results and discussion}

In this study, the effect of $\mathrm{Cr}(\mathrm{VI})$ on OPC hydration was evaluated by continuous observing of early hydration. For these measurements microcalorimetry was applied, which monitors 


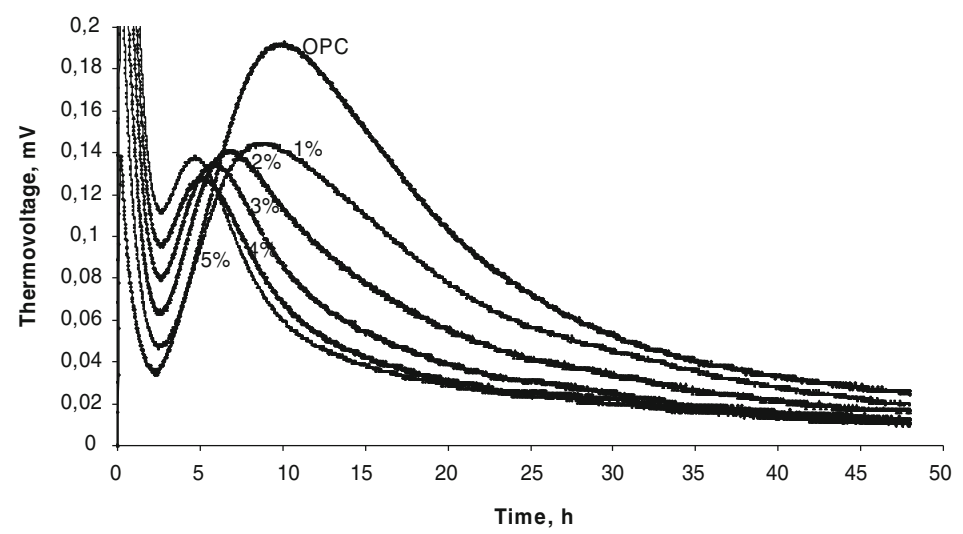

Figure 1. Thermovoltage curves for cement samples with different addition of chromium salt.

heat released during hydration. The released heat causes the operating cell of a differential microcalorimeter for a difference of temperatures between the operating and the referent cell, measured as voltage difference, $\mathrm{dU}$, by thermocouples.

Figure 1 shows the thermovoltage curves for cement samples with different addition of chromium salt. The curves obtained on thermovoltage are very pronounced second maximum. Increasing the content of chromium salt maximums assume lower values and the occurrence of the maximum registered in the earlier hydration times.

As can be seen, the basic shapes of the termovoltage curves with the additions are very similar to the curve for the sample of OPC without addition. This indicates that the chromium salt does not affect the hydration mechanisms and processes of stabilization. The OPC pastes without addition show the highest values for heat of hydration $(\mathrm{Q}=192 \mathrm{~J} / \mathrm{g})$ after $48 \mathrm{~h}$ of hydration and reaches its maximum after $10.63 \mathrm{~h}$. Cement composites with maximum content of chromium salt show the lowest values for heat of hydration $(\mathrm{Q}=115.91 \mathrm{~J} / \mathrm{g})$ and the maximum is reached after $4.97 \mathrm{~h}$ of hydration.

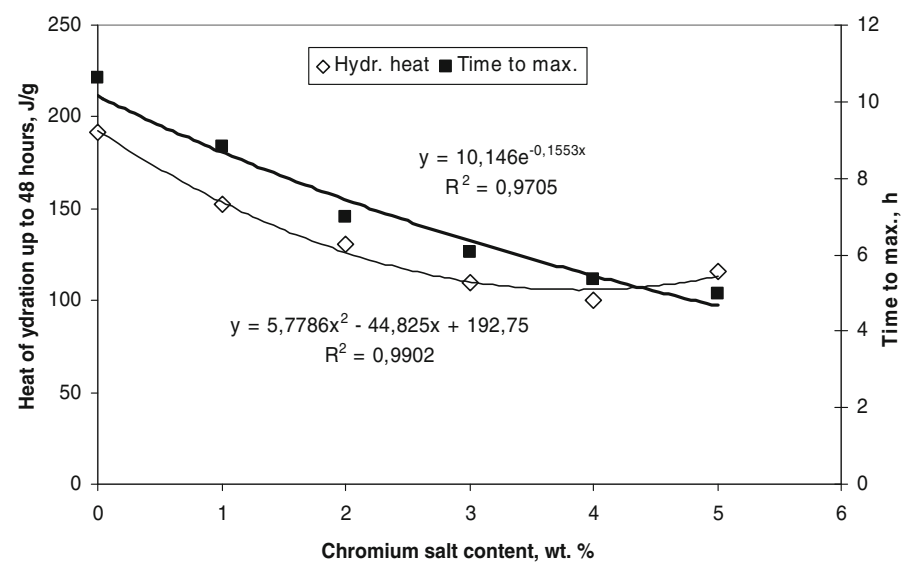

Figure 2. Heat of hydration up to $48 \mathrm{~h}$ and time to maximum relative to the content of chromium salt. 


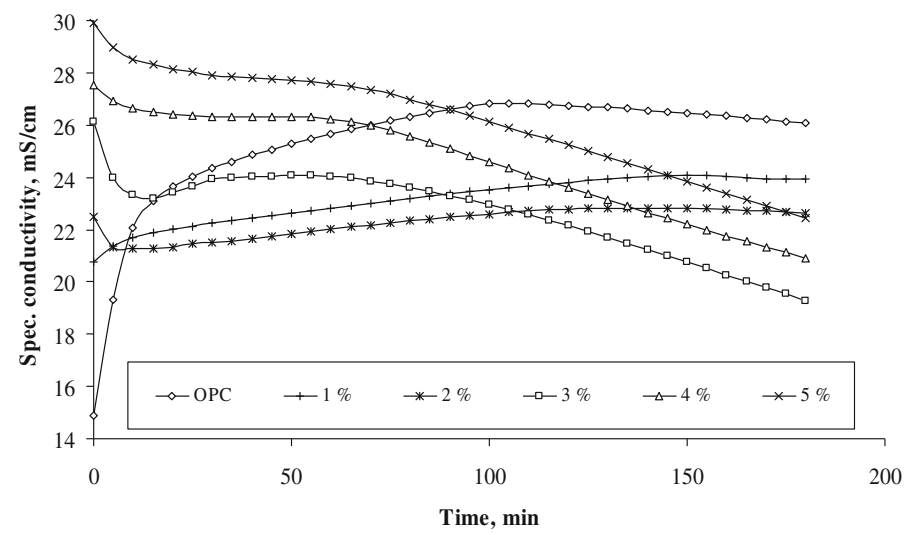

Figure 3. Dependence of conductivity on the hydration time of cement pastes with addition of chromium salt.

The analysis of data from figure 2 yielded a mathematical relation of maximum heat of hydration relative to the addition of content.

For the addition of chromium salt, the function of heat of hydration has the form $y=5.7786 x^{2}$ $-44.825 \mathrm{x}+192.75$, where $\mathrm{y}$ is the maximum heat released $(\mathrm{J} / \mathrm{g})$ and $\mathrm{x}$ represents addition of chromium salt in wt.\%. Time to heat maximum can be calculated by the equation $\mathrm{z}=$ $10.146 \mathrm{e}^{-0.1553 x}$, where $\mathrm{z}$ is the time in hours, and $\mathrm{x}$ is the addition of content.

The results show that the chromium salt has a strong effect on the hydration processes and reactions. The main reason is the slow nucleation of hydration products in the outer, preliminary dissolved layer, and low, gradually growing up concentration of ions in the surrounding liquid phase. Subsequently, the induction period is followed by the acceleration of hydration due to the crystallization of hydrates and further decomposition of anhydrous substance.

Conductometrical measurements were carried out to determine the initial bonding time of the cement composites, as a parameter for judging the success solidification and stabilization of chromium salt (EN 196-3), which is reflected by the appearance of a maximum in specific conductivity curves (figure 3). According to standard EN 196-3 for OPC, the beginning of binding

Table 3. Time to occurrence of maximum conductivity for various addition of chromium salt.

\begin{tabular}{lc}
\hline $\begin{array}{l}\text { Addition } \\
\text { of chromium } \\
\text { (wt.\%) }\end{array}$ & $\begin{array}{c}\text { Time to occurrence } \\
\text { of maximum conductivity } \\
\text { (min) }\end{array}$ \\
\hline 0 & 105 \\
1 & 150 \\
2 & 145 \\
3 & 50 \\
4 & 50 \\
5 & 45 \\
\hline
\end{tabular}




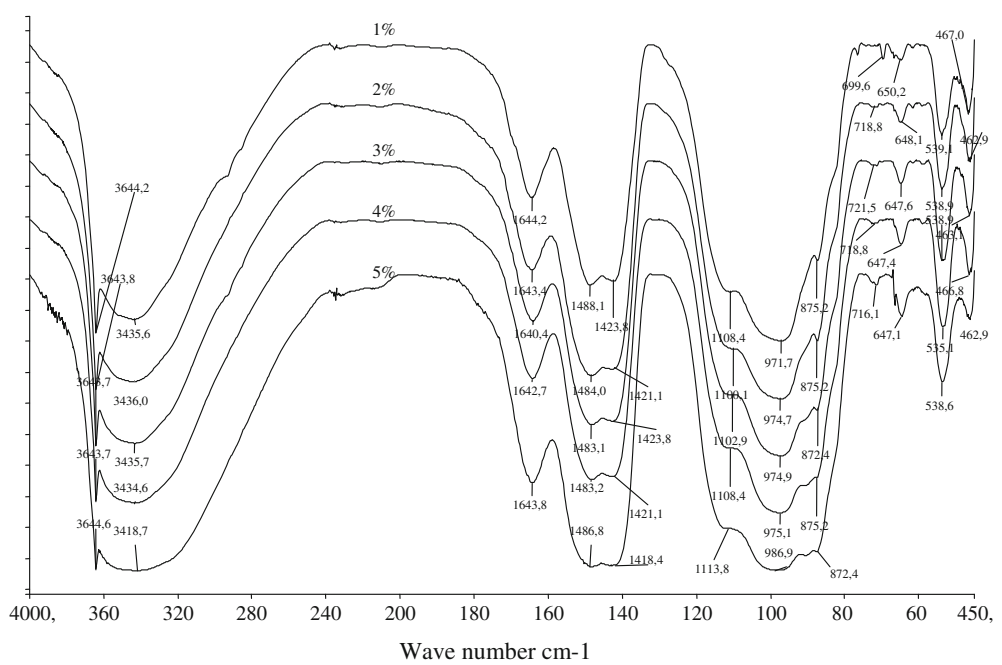

Figure 4. FTIR spectra of cement pastes with addition of chromium salt.

time should occur after 60 minutes. For the practical application, the end of binding time should happen in time below 200 minutes.

It can be seen that with increasing addition of chromium salt, no peaks are observed in the curve, specific conductivity immediately drops and the maximum is reached soon. Microcalorimetrical results show that addition of chromium salt in the cement-water system is acceptable up to 2 wt.\% (table 3). Increased contents of chromium over 2 wt.\% significantly accelerate the beginning of binding time and for the system which is not acceptable.

FTIR data show that changes in the silicate and carbonate phases when chromium salt is mixed with OPC (figure 4).

The results show very sharp peak at $3645 \mathrm{~cm}^{-1}$. This is attributed to the $\mathrm{O}-\mathrm{H}$ stretching of $\mathrm{Ca}(\mathrm{OH})_{2}$ (Bensted \& Varna 1974). The band of $3450 \mathrm{~cm}^{-1}$ is caused by the symmetric and asymmetric stretching of the water molecules. The band at $1645 \mathrm{~cm}^{-1}$ corresponds to the deformation mode of the molecular water. Additional bands at approximately 1425, 1497, 875 and $732 \mathrm{~cm}^{-1}$ correspond to $v_{3}, v_{2}$ and $v_{4} \mathrm{CO}_{3}^{2-}$. Comparing the bands of silicate in the range 969$987 \mathrm{~cm}^{-1}$ for samples with and without addition of chromium salt it shows that $v_{3} \mathrm{SiO}_{4}^{4-}$ bands shifted to higher frequencies suggesting a slightly higher degree of polymerization of the silicate units in the presence of chromium. But, it is difficult to draw conclusions from the FTIR results.

\section{Conclusions}

In this study, the effect of $\mathrm{Cr}(\mathrm{VI})$ on OPC hydration was evaluated by continuous observing of early hydration. The microcalorimetrical results show that with increasing the content of chromium salt, heat maximums assume lower values and they are registered in the earlier hydration times. Conductometrical measurements show that with increasing addition of chromium salt, curve did not show a specific shape, specific conductivity immediately drops and the maximum is reached soon. This coincides with microcalorimetrical results. The addition of chromium does not affect the mechanism of the hydration process, but it does affect the kinetic parameters and dynamics of the cement hydration process. It was found that chromium salt addition to the 
cement-water system is acceptable up to $2 \mathrm{wt} \%$. Increased shares of chromium over $2 \mathrm{wt} \%$ significantly accelerate the beginning of binding time and it is not acceptable for the system.

\section{Acknowledgements}

The authors wish to thank the Ministry of Science, Education and Sport of the Republic of Croatia, for financing this research project (a part of the study is presented in this report).

\section{References}

Bartlett R J J 1991 Chromium cycling in soils and water: links, gaps, and methods. Environ. Health Prospect 92: $17-24$

Bensted J and Varna S P 1974 Some applications of IR and Raman Spectroscopy in cement chemistry, Part III: Hydration of Portland cement and its constituents. Cement Technol. 5(5): 440-442

EPA 1994 Natural attenuation of hexavalent chromium in groundwater and soils, EPA, Washington, DC.

Giergiczny Z and Krol A 2008 Immobilization of heavy metals ( $\mathrm{Pb}, \mathrm{Cu}, \mathrm{Cr}, \mathrm{Zn}, \mathrm{Cd}, \mathrm{Mn}$ ) in the mineral additions containing concrete composites. J. Hazard. Mater. 160: 247-255

Katz S A and Salem H 1994 The biological and environmental chemistry of chromium New York: VCH Publications

Krstulović R, Krolo P and Ferić T 1989 Microcalorimetry in cement hydration process. Periodica Polytehnica 33: 315-321

Otomoso O E, Ivey D G and Mikula R 1995 Electron microscopic and 29Si-nuclear magnetic resonance spectroscopic studies of chromium doped tricalcium silicate, J P Hager, B Mishra, C F Davidson and $\mathrm{J}$ L Litz (eds.), Treatment and minimisation of heavy metal-containing wastes, 129

Pera J, Thevenin G and Chabannet M 1997 Design of a novel system allowing the selection of an adequate binder for solidification/stabilization of wastes. Cem. Conc. Res. 27: 1533-1542

Shi H and Kan L 2009 Study on the properties of chromium residue-cement matrices (CRCM) and the influences of superplasticizers on chromium(VI)-immobilising capability of cement matrices. J. Hazard. Mater. 162: 913-919

Spence R D and Shi C 2005 Stabilization and solidification of hazardous, radioactive, and mixed wastes Boca-Raton: CRC Press

Taylor H F W 1997 Cement chemistry. 2nd ed., London: Thomas Telford Publishing, 113-224

Trezza M A and Scian A N 2007 Waste with chrome in the Portland cement clinker production. J. Hazard. Mater. 147: 188-196

Wang S and Vipulanandan C 2000 Solidification/stabilization of $\mathrm{Cr}(\mathrm{VI})$ with cement: Leachability and XRD analyses. Cement Con. Res. 30: 385-389

Zamorani E, Sheikh I A, Della Rosa M, Serrini G 1989 In: Physical properties and leachability of MLW stream containing $\mathrm{Cr}$, Ni and Cd immobilised in a cement matrix, W Lutze and R C Ewing (eds.), Mater. Res. Soc. Symp. Proc. 127: 489-494 